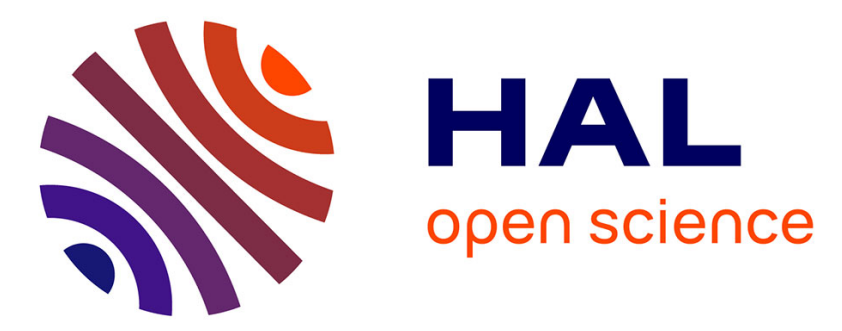

\title{
Room temperature plasticity and phase transformation of nanometer-sized transition alumina nanoparticles under pressure
}

I. Issa, Lucile Joly-Pottuz, Julien Réthoré, C. Esnouf, Thierry Douillard, V. Garnier, Jérome Chevalier, S. Le Floch, D. Machon, Karine Masenelli-Varlot

\section{To cite this version:}

I. Issa, Lucile Joly-Pottuz, Julien Réthoré, C. Esnouf, Thierry Douillard, et al.. Room temperature plasticity and phase transformation of nanometer-sized transition alumina nanoparticles under pressure. Acta Materialia, 2018, 150, pp.308-316. 10.1016/j.actamat.2018.03.023 . hal-01757849

\author{
HAL Id: hal-01757849 \\ https://hal.science/hal-01757849
}

Submitted on 3 May 2021

HAL is a multi-disciplinary open access archive for the deposit and dissemination of scientific research documents, whether they are published or not. The documents may come from teaching and research institutions in France or abroad, or from public or private research centers.
L'archive ouverte pluridisciplinaire HAL, est destinée au dépôt et à la diffusion de documents scientifiques de niveau recherche, publiés ou non, émanant des établissements d'enseignement et de recherche français ou étrangers, des laboratoires publics ou privés.

\section{(c)(1)}

Distributed under a Creative Commons Attribution| 4.0 International License 


\title{
Room temperature plasticity and phase transformation of nanometer- sized transition alumina nanoparticles under pressure
}

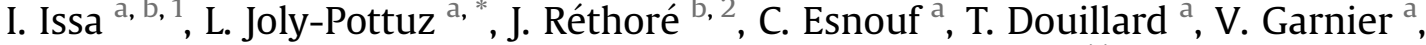 \\ J. Chevalier ${ }^{\mathrm{a}}$, S. Le Floch ${ }^{\mathrm{c}}$, D. Machon ${ }^{\mathrm{c}}$, K. Masenelli-Varlot ${ }^{\mathrm{a}, * *}$ \\ ${ }^{a}$ Univ Lyon, INSA-Lyon, MATEIS CNRS UMR5510, 69621 Villeurbanne, France \\ b Univ Lyon, INSA-Lyon LaMCoS CNRS UMR5259, 69621 Villeurbanne, France

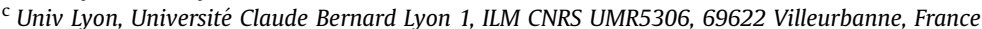

\begin{abstract}
A powder of transition alumina nanoparticles (including $\gamma$ and a so-called $\delta$-type) is compacted at room temperature in a diamond anvil cell (DAC) under pressures ranging from $5 \mathrm{GPa}$ to $20 \mathrm{GPa}$. Characterization carried out on thin foils prepared by focused ion beam (FIB), from the compacted powder, unambiguously reveals plasticity. High resolution transmission electron microscopy (HRTEM) and electron diffraction also evidence phase transformation of nanoparticles under high pressure and nanoparticles show faceting parallel to the loading direction with a preferential crystallographic orientation of the facets corresponding to $\{220\}$ planes of $\gamma-\mathrm{Al}_{2} \mathrm{O}_{3}$. It can also be deduced, from the comparison between the DAC experiments and in situ TEM nano-compression tests on single particles performed in a preceding work, that plasticity is driven by slip bands corresponding to $\{111\}$ slip planes, common for a spinel structure, such as, for instance, $\gamma-\mathrm{Al}_{2} \mathrm{O}_{3}$.

We also demonstrate that at ambient temperature the transition alumina phase is also prone to structural change under high pressures with the following sequence $\gamma-\mathrm{Al}_{2} \mathrm{O}_{3} \rightarrow \delta^{*} \mathrm{Al}_{2} \mathrm{O}_{3}$, these two phases coexisting, sometimes, in the same nanoparticle after compaction. Plasticity at room temperature in alumina nanoparticles and the subsequent phase transformation under pressure may have strong impacts on the process of alumina nanostructured ceramics.
\end{abstract}

\section{Introduction}

Ceramics have always been considered as brittle materials at room temperature. Nevertheless, recent studies show that they can present a plastic behavior at the nanometer scale [1,2]. This peculiar behavior for ceramic materials may have a strong impact either on their processing [3] or their future use, since it would open the door towards low-temperature forming, followed by much more moderate sintering temperatures. Nanometer-sized ceramic

\footnotetext{
* Corresponding author. MATEIS, bâtiment Blaise Pascal, INSA-Lyon, 7 avenue Jean Capelle, 69621 Villeurbanne cedex, France.

** Corresponding author. MATEIS, bâtiment Blaise Pascal, INSA-Lyon, 7 avenue Jean Capelle, 69621 Villeurbanne cedex, France.

E-mail addresses: Lucile.Joly-Pottuz@insa-lyon.fr (L. Joly-Pottuz), Karine. Masenelli-Varlot@insa-lyon.fr (K. Masenelli-Varlot).

${ }^{1}$ Now at Erich Schmid Institute of Materials Science, Montanuniversität Leoben, Jahnstrasse 12, 8700 Leoben, Austria.

${ }^{2}$ Now at GeM institute, Cnrs, Ecole Centrale de Nantes, UMR 6183, France.
}

nanoparticles are nowadays mostly used for the processing of bulk ceramics like, for instance, nanocomposites for biomedical applications [4-6]. The aim of using nanometer-sized particles is to obtain nanometer-sized grains after sintering. The so-called nanoceramics exhibit extraordinarily good mechanical properties like high wear resistance, low friction, and high strength and hardness [7]. In the case of alumina, the absence of porosity and the nanometer grain size are key points to enhance transparency [8-11]. Thanks to these outstanding properties, many other applications could be considered $[12,13]$. Understanding the plastic behavior of nanometer-sized ceramic nanoparticles is one possible research axis in order to keep their nanometer size during processing. Our first results obtained during in situ nano-solicitation experiments in Transmission Electron Microscopy (TEM) revealed a surprising behavior for transition alumina and $\mathrm{MgO}$ nanoparticles: plasticity at room temperature [1,2]. In the case of $\mathrm{MgO}$, this was also observed by Korte and Clegg on micropillars previously prepared by Focused Ion Beam (FIB) [14]. Kiani et al. also used FIB sample 
preparation to study room temperature plasticity in $\mathrm{ZrC}$ pillars [15]. The advantage of such in situ tests in the case of alumina lies in the fact that it is also possible to test transition phases (metastable phases of alumina) which do not exist at the microscale and as bulk material. Indeed, $\boldsymbol{\alpha}$-alumina is the only phase of alumina that is stable at bulk, under a wide range of pressures and temperatures [16] while nanometer-sized powders generally consist in a mixture of transition alumina. Studying the behavior of transition alumina is of much interest. Liao et al. [17] showed that the strong compaction of transition alumina (perfectly spherical nanoparticles) improves the green density up to $83 \%$ at a pressure of $8 \mathrm{GPa}$. They concluded, without evidence, that the high density could be linked to a possible partial plastic deformation of transition alumina nanoparticles.

In addition to pressure-assisted plasticity, structural changes may also occur during compression. To investigate possible phase transformation, the different crystallographic phases of alumina can first be briefly introduced. The structure adopted by $\alpha-\mathrm{Al}_{2} \mathrm{O}_{3}$ can be described by oxygen anions in a near hexagonal compact arrangement and cations filling 2/3 of the octahedral sites. As a consequence, the $\alpha-\mathrm{Al}_{2} \mathrm{O}_{3}$ structure contains vacancies that are present in $1 / 3$ of the octahedral sites in an ordered array and wellknown sequence along a rhombohedral structures axis $\left(2 \mathrm{Al}^{3+}\right.$ -vacancy- $\left.2 \mathrm{Al}^{3+}\right)$. Transition alumina phases $(\gamma, \delta, \eta, \theta)$ are described by the spinel structure defined by the chemical formula $\mathrm{AB}_{2} \mathrm{O}_{4}$, here $\mathrm{Al}_{3} \mathrm{O}_{4}$. However as far as stoichiometry is concerned, alumina is described by the chemical formula $\mathrm{Al}_{2} \mathrm{O}_{3}$. This means that the structure contains $\mathrm{Al}^{3+}$ vacancies. In all transition alumina phases, the oxygen anions are nearly in a face-centered cubic arrangement and cations are occupying octahedral and tetrahedral sites. Each phase of transition alumina presents a specific percentage of cations occupation of the octahedral sites over the tetrahedral sites, inducing a specific cations arrangement in each transition alumina phase. For instance, the cation arrangement can be described by cubic and tetragonal structures for $\gamma-\mathrm{Al}_{2} \mathrm{O}_{3}$ and $\delta$ $\mathrm{Al}_{2} \mathrm{O}_{3}$ respectively, with a certain number of randomly distributed vacancies in each unit cell. The $\delta-\mathrm{Al}_{2} \mathrm{O}_{3}$ tetragonal variety is a quasisupercell of $\gamma-\mathrm{Al}_{2} \mathrm{O}_{3}$ parameters a, b of its cell are very close to those of the $\gamma$ phase divided by $\sqrt{2}$ and its c parameter is close to 3 times that of the $\gamma$ one (JCPDS file 46-1131). Therefore, the main diffraction peaks of tetragonal $\delta-\mathrm{Al}_{2} \mathrm{O}_{3}$ are in quasi-coincidence with those relative to the $\gamma$ phase. Only weak supplementary peaks for high inter-reticular distances are present in the $\delta$ phase. Other transition alumina phases are also found in the literature. In particular, the $\mathrm{Al}^{3+}$ cations can be arranged in an orthorhombic structure, leading to the phase $\delta^{*}-\mathrm{Al}_{2} \mathrm{O}_{3}$ [18], also called "orthorhombic $\delta-\mathrm{Al}_{2} \mathrm{O}_{3}$ " by Levin et al. [19]. This phase can be quite easily distinguished from the $\gamma$ one by X-ray diffraction (see Fig. 1).

For surface areas lower than $125 \mathrm{~m}^{2} / \mathrm{g}$, the $\alpha$-phase is the most stable one, whereas transition phases are metastable [20]. A sequence of high temperature processes that enables phase transformations from boehmite towards transition alumina and then to $\alpha$-Alumina is given by Refs. [19,21]:

$$
\begin{aligned}
& \gamma-\mathrm{AlOOH}(\text { Boehmite }) \rightarrow \gamma-\mathrm{Al}_{2} \mathrm{O}_{3} \rightarrow \delta-\mathrm{Al}_{2} \mathrm{O}_{3} \rightarrow \theta-\mathrm{Al}_{2} \mathrm{O}_{3} \rightarrow \alpha \\
& -\mathrm{Al}_{2} \mathrm{O}_{3}
\end{aligned}
$$

These transformations are not reversible as each phase obtained after a transition is preserved when temperature is decreased down to room temperature. As mentioned previously, some other intermediate phases $\left(\delta^{*}, \delta^{\prime}\right)$, not present in this sequence, may also be found. As a consequence, it has been suggested that transformation from $\gamma-\mathrm{Al}_{2} \mathrm{O}_{3}$ (cubic) to $\delta^{*}-\mathrm{Al}_{2} \mathrm{O}_{3}$ (orthorhombic) occurs before the cubic spinel collapse and exhibits a tetragonal character $\left(\delta-\mathrm{Al}_{2} \mathrm{O}_{3}\right)$.

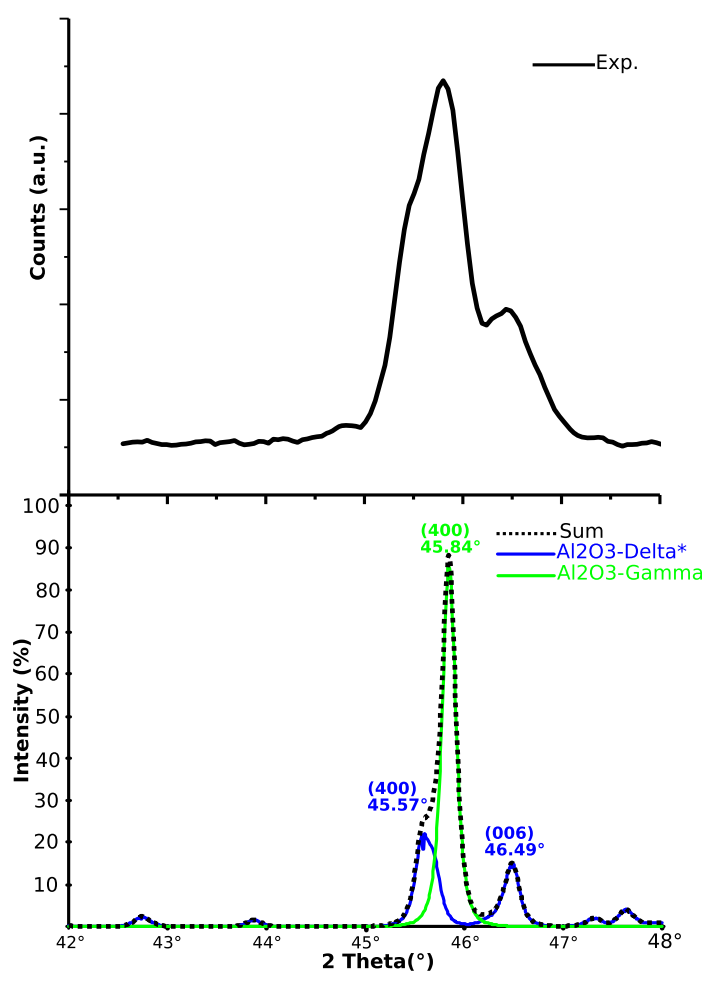

Fig. 1. Phase indexation in the native nanoparticles. Upper part: experimental X-Ray diffractogram. Lower part: simulated XRD diffractogram for a mixture of $\gamma-\mathrm{Al}_{2} \mathrm{O}_{3}$ (70 wt.\%) and $\delta^{*}-\mathrm{Al}_{2} \mathrm{O}_{3}$ (30 wt.\%) calculated with the software of Carine Crystallography 3.1.

This is followed by a monoclinic structure $\left(\theta-\mathrm{Al}_{2} \mathrm{O}_{3}\right)$ transformation and finally at higher temperature the trigonal structure $\alpha-\mathrm{Al}_{2} \mathrm{O}_{3}$ is obtained (without any occupancy of the tetrahedral sites by cations) [19]. It has to be mentioned as well that although some other sequences have been proposed in the literature, for instance by Macêdo et al. [22] or by Paglia et al. [23], there is a lack of information about the physical parameters involved into these phase transformations. For example, temperature is known to trigger phases transformations [17,23], but $\alpha$ alumina is also sensitive to structural changes at high pressure (90 GPa) [24].

As the fabrication of bulk nanostructured alumina includes the compaction of green samples made of transition alumina nanoparticles, which turned out to exhibit a plastic behavior at room temperature, it is necessary to understand better the behavior of the nanoparticles during compaction. In this study, we aim at using a diamond anvil cell (DAC) to compact a powder of transition alumina nanoparticles at room temperature. DAC allows compacting the powder with relatively high pressures $(20 \mathrm{GPa}$ in our study), and we may expect locally high stresses which may trigger plasticity and/or phase transformation at ambient temperature. In addition to a deep characterization of the compacted powder, our objective is also to correlate the results obtained with in situ previous nano-compression experiments in TEM, where plastic behavior of individual crystalline particles was observed in real time $[1,25]$.

\section{Materials and methods}

The transition alumina nanoparticles used in this study have been produced by Nanophase Technologies Corporation (Romeoville, IL, USA). It is thermally treated at $900{ }^{\circ} \mathrm{C}$ to improve its crystallinity. The particles are spherical and the size distribution lies 
between a few of $\mathrm{nm}$ and $150 \mathrm{~nm}$, with an average diameter around $20 \mathrm{~nm}$ [26]. HRTEM images obtained from several nanoparticles confirm their crystallinity [25]. Occasionally, few twin boundaries can be observed but only few particles are concerned [25].

The crystallographic phases were determined by X-ray diffraction on a $\theta-\theta$ Bruker D8 Advance System (Bruker AXS Gmbh, Germany) using $\mathrm{Cu} K \alpha$ radiation $(\lambda=0.154 \mathrm{~nm})$. The working voltage of the instrument was $40 \mathrm{kV}$ with a current of $40 \mathrm{~mA}$.

To ensure a good filling of the DAC gasket, the powder has been granulated by atomization. Granules exhibit sizes around $50 \mu \mathrm{m}$ with a nanoparticle packing of $69 \%$ inside the granules [27]. The granulated alumina nanoparticles have been compacted in a DAC equipped with a $200 \mu \mathrm{m}$-thick steel gasket. A hole of $60 \mu \mathrm{m}$ in thickness and $300 \mu \mathrm{m}$ in diameter was previously drilled in the gasket to introduce several close-packed granules in the DAC. A ruby has also been inserted in the hole for pressure calibration. No transmitting media has been used to favor free motion and stacking of the nanoparticles. Three uniaxial compression experiments have been performed at $5 \mathrm{GPa}, 15 \mathrm{GPa}$ and $20 \mathrm{GPa}$. As shown recently, the pressure measured by the ruby luminescence even in presence of highly non-hydrostatic components is a pertinent parameter to study the mechanical properties of a nanopowder by giving an average pressure that corresponds to the load on the powder [28].

Thin foils have been extracted from the compacted samples using a FIB/SEM (NVision 40; Carl Zeiss Microscopy GmbH, Oberkochen, Germany), equipped with a multi-nozzle SIINT gas injection system (GIS) and a Cartesian nano-robotic manipulator (Klocke Nanotechnik GmbH, Aachen, Germany). To minimize the curtain effect introduced by the gallium ion beam milling and to protect the sample surface from implantation, an in situ ion beam induced deposition has first been performed over the area of interest with tungsten carboxyl $\mathrm{W}(\mathrm{CO})_{6}$ as a precursor gas (sputter-resistant layer of about $1 \mu \mathrm{m})$. Trenches have been milled to enable the extraction of $1-2 \mu \mathrm{m}$ thick lamellas which have then been transferred, using the manipulator, and glued, using the GIS, onto a TEM copper grid for further thinning. In this work, settings for $30 \mathrm{kV}$ ion accelerating voltage with decreasing beam currents ( $700 \mathrm{pA}-40 \mathrm{pA}$ ) and probe sizes have been used to reach a suitable foil thickness for TEM analysis (around $100 \mathrm{~nm}$ ). At each step, milling has been carried out using an adjusted grazing incidence to compensate for the ion beam tails in order to achieve near parallel foil top and bottom surfaces over a large zone. Finally, to reduce the amorphous layer due to the high energy ion beam, a final low-kV ion polishing at $2 \mathrm{kV} / 50 \mathrm{pA}$ has been performed.

The observations have been carried out on a JEOL 2010F field emission electron microscope operating at $200 \mathrm{kV}$ (with a point resolution of $0.2 \mathrm{~nm}$ ). The size distribution of the deformed particles has been determined through numerical analysis of bright field TEM images acquired at low magnification. Series of HRTEM images have been taken at the surface contacts between two deformed nanoparticles on the samples compacted at $5 \mathrm{GPa}, 15 \mathrm{GPa}$ and $20 \mathrm{GPa}$. The Fast Fourier Transforms (FFT), reproducing diffraction patterns of specific regions of interest, have been indexed. Indexations are based on inter-reticular distances and angles between planes. The JCPDS tables used for the phase indexation are the following ones: 00-050-0741 $(\gamma), 00-046-1215\left(\delta^{*}\right)$ and 00-047$1770(\delta)$. Because of the high density of the sample compacted at $20 \mathrm{GPa}$, it has been hardly possible to perform high resolution imaging like on the samples compacted at lower pressures. Therefore, classical selected area (SA) diffraction patterns of the sample compacted at $20 \mathrm{GPa}$ have been acquired and indexed.

Simulations of the theoretical X-ray diffractogram have been performed by using Carine Crystallography 3.1 on the basis of the Wyckoff positions given by Zhou and Snyder [29] and Fargeot et al. [18] for $\gamma$ and $\delta^{*}$, respectively. As far as Debye Scherrer electron diffraction patterns are concerned, the intensity profiles have been measured by circular integration in Digital Micrograph ${ }^{\mathrm{TM}}$ software of GATAN. The intensity profiles have also been corrected by considering the beam stop shape. In order to calculate the theoretical electron diffraction profiles, we used data from JEMS software [30]. The structural parameters of $\gamma-\mathrm{Al}_{2} \mathrm{O}_{3}$ and $\delta^{*}-\mathrm{Al}_{2} \mathrm{O}_{3}$ are also based on the papers published in the literature $[18,28]$.

\section{Results}

A portion of a X-ray diffractogram obtained on the native powder is shown in Fig. 1. Several peaks overlap in the $2 \theta$ region $45-47^{\circ}$. This requires an accurate indexation as inter-reticular distances in some of the transition alumina are very close to each other, like for instance in the case of $\gamma-\mathrm{Al}_{2} \mathrm{O}_{3}, \delta-\mathrm{Al}_{2} \mathrm{O}_{3}$ and $\delta *-\mathrm{Al}_{2} \mathrm{O}_{3}$. However, in this range of diffraction angles, the diffractions peaks relative to $\delta^{*}-\mathrm{Al}_{2} \mathrm{O}_{3}$ occur at different angles compare with those of $\gamma-\mathrm{Al}_{2} \mathrm{O}_{3}$ and $\delta-\mathrm{Al}_{2} \mathrm{O}_{3}$, which make the identification of the phase $\delta^{*}$ $\mathrm{Al}_{2} \mathrm{O}_{3}$ relatively straightforward (see Fig. 1). On the contrary in this region, the phases $\gamma-\mathrm{Al}_{2} \mathrm{O}_{3}$ and $\delta-\mathrm{Al}_{2} \mathrm{O}_{3}$ cannot be distinguished from each other. As $\gamma-\mathrm{Al}_{2} \mathrm{O}_{3}$ can be unambiguously evidenced in a large number of HRTEM images (see below), we use here only $\gamma$ $\mathrm{Al}_{2} \mathrm{O}_{3}$ and $\delta^{*}-\mathrm{Al}_{2} \mathrm{O}_{3}$ for the simulations. The theoretical composition that gives the best fit with the experimental diffractogram is made of $70 \mathrm{wt} . \%$ of $\gamma-\mathrm{Al}_{2} \mathrm{O}_{3}$ and $30 \mathrm{wt} . \%$ of $\delta^{*}-\mathrm{Al}_{2} \mathrm{O}_{3}$. The difference in the width of peaks between experimental and simulated patterns is essentially due to the small size of particles: according the Scherrer relation, the angular full width at half maximum is close to $0.5^{\circ}$ for a particle size of $17 \mathrm{~nm}$.

Observations of the three samples after compaction reveal that only the smallest particles, below $90 \mathrm{~nm}$ in size, are deformed under a pressure in the DAC of $5 \mathrm{GPa}$ (see Fig. 2). At higher pressures ( 15 and especially $20 \mathrm{GPa}$ ), almost all the particles are distorted. The density of the samples compacted at 15 and $20 \mathrm{GPa}$ is very high, without any residual porosity observed at $20 \mathrm{GPa}$. One can notice the progressive decrease of porosity under increasing pressures. At $20 \mathrm{GPa}$, the white contours around the particles are a TEM imaging effect due to defocus used to give a better estimation of the particle boundaries.

Facets are observed in all the samples, and more clearly in the sample compacted at $20 \mathrm{GPa}$. They appear to be parallel to each other and parallel to the principal solicitation direction (see Fig. 3b). This texture can be observed until $1 \mu \mathrm{m}$ below the sample surface (see Fig. 3a). Below this depth, the texture seems to be slightly tilted and seems to be localized in small domains of several nanoparticles that are not perfectly aligned one to other.

At $5 \mathrm{GPa}$, the indexation of the electronic diffraction patterns obtained on deformed nanoparticles is compatible with the $\gamma$ phase. Interestingly, a preferred crystallographic orientation is observed for the deformed nanoparticles. The $\{220\}$ planes of the $\gamma$ phase are indeed found to be parallel to the surface in contact with the neighboring nanoparticle. This preferential crystallographic orientation, with the $\{220\}$ planes parallel to the contact surface, can be evidenced in almost all indexed HRTEM images of deformed nanoparticles having clear contact surfaces. Fig. 4 presents 3 deformed particles, one of them having an interesting zone axis (on the right part of the image). On this particle, two facets can be observed, making an angle close to $120^{\circ}$. The $\{220\}$ family of planes contains 12 planes. The angles values between these different planes are equal either to $60^{\circ}$, to $90^{\circ}$ or to $120^{\circ}$. The indexation and the angle are thus consistent and confirm that the facets are $\{220\}$ planes. FFT indexations from regions of interest in the samples compacted at $15 \mathrm{GPa}$ and $20 \mathrm{GPa}$ confirm, if the particles are in the $\gamma$-phase, that one of the $\{220\}$ planes is always parallel to the contact surface between particles. 

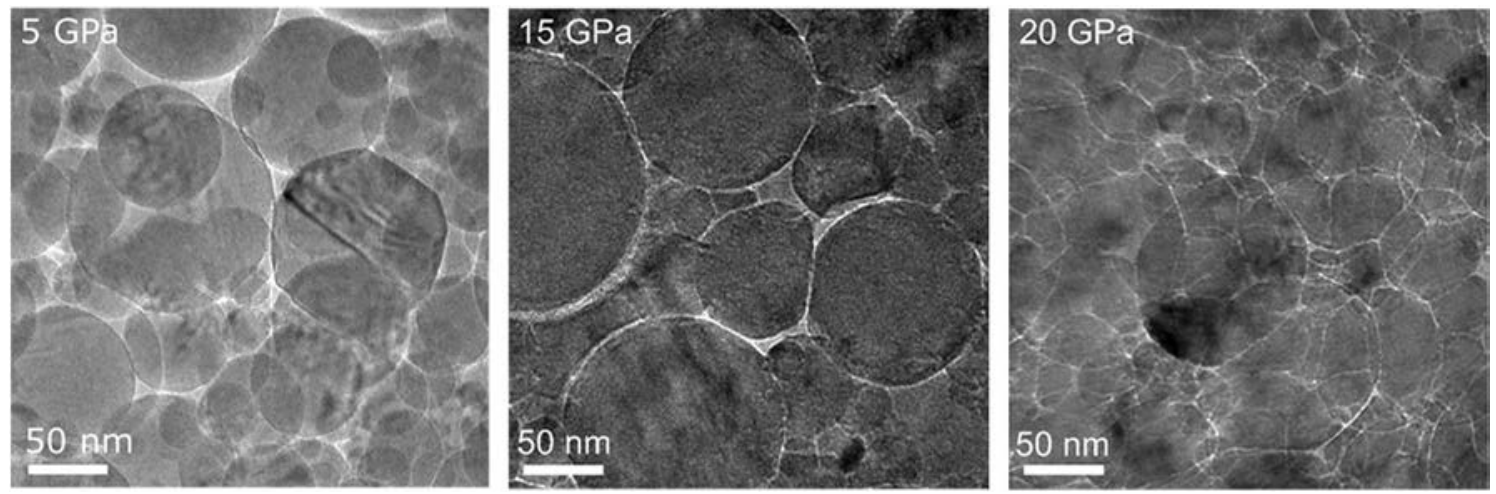

Fig. 2. TEM observations of the compacted samples at three pressures: $5 \mathrm{GPa}, 15 \mathrm{GPa}$ and $20 \mathrm{GPa}$.
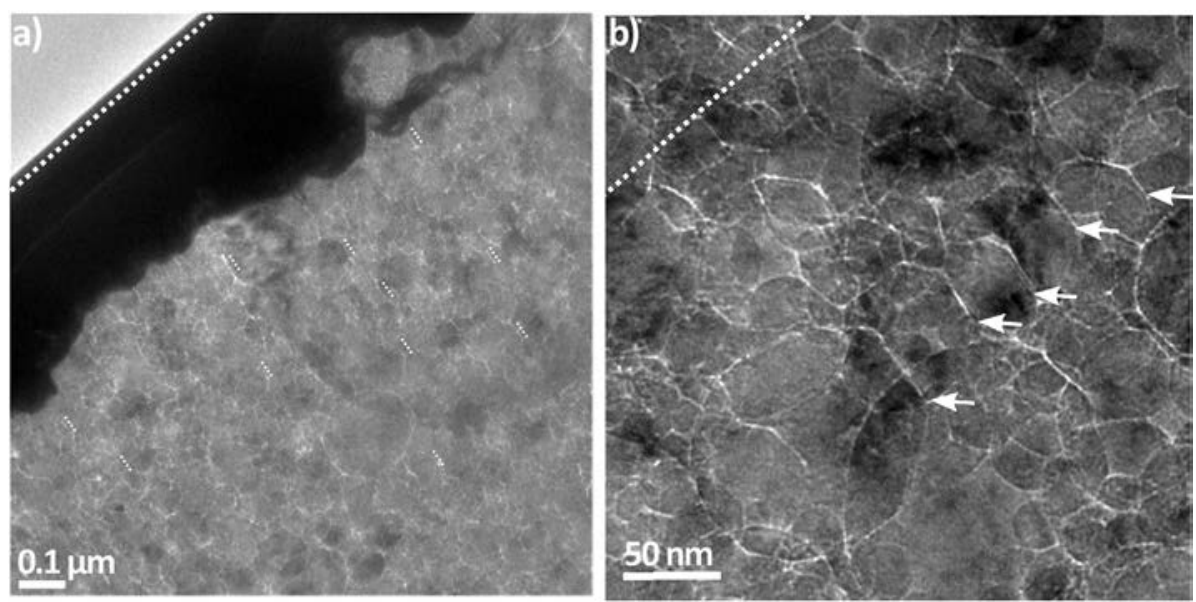

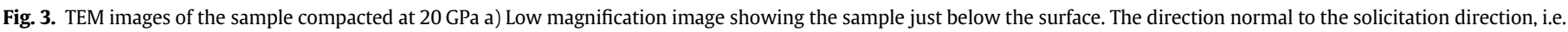

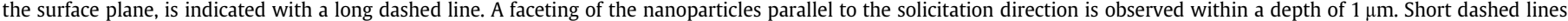

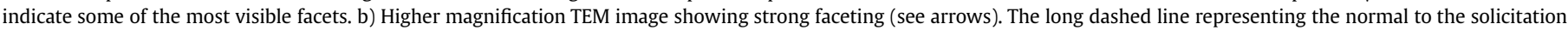
direction is also shown.

Table 1 summarizes the results obtained on the indexed deformed nanoparticles at different pressures. At $5 \mathrm{GPa}$, the 15 deformed nanoparticles analyzed are in the $\gamma$-phase only. At higher pressures, other phases, namely $\delta$ and $\delta^{*}$, are also found in the deformed nanoparticles. Fig. 5 presents a particle after compaction at $20 \mathrm{GPa}$. Several domains can be found in the particle. The indexation of the FFTs in different regions of interest reveals the presence of the $\gamma$-phase in the center of the nanoparticle, while the periphery is in $\delta$ phase.

In order to analyze a larger number of particles, Debye-Scherrer patterns have been acquired on the three samples. X-ray microdiffraction was first considered after compaction to characterize the phases but it was unfortunately not possible to analyze the sample due to the presence of the metallic gasket used for DAC. The Debye-Scherrer patterns acquired from electron diffraction confirm the presence of $\gamma$ and $\delta^{*}$ phases in all the samples, as in the native powder. From electron diffraction patterns obtained on single phase nanoparticles, the presence of superstructures sometimes reveal the presence of the $\delta$ phase in the sample compacted at $20 \mathrm{GPa}$.

Intensity profiles extracted from the Debye Scherrer patterns on the initial powder $(0 \mathrm{GPa})$ and the samples compacted at 5 and $20 \mathrm{GPa}$ are displayed in Fig. 6. The background intensity becomes very high at large inter-reticular distances, near the diffraction pattern centre. Nevertheless, it is still possible to identify the peaks at 3.57 and $4.18 \mathrm{~nm}^{-1}$. They respectively correspond to the planes $\{220\}$ and $\{311\}$ of the $\gamma$-phase in the diffraction profile of the initial powder, see Fig. 7. The peaks of the $\delta^{*}$-phase in this range of $\mathrm{d}^{-1}$, are hardly visible in the experimental profile of the initial powder. For comparison purposes, Fig. 7 also includes simulated electron diffraction profiles for one unit cell of $\gamma-\mathrm{Al}_{2} \mathrm{O}_{3}$ and one unit cell of $\delta^{*}-\mathrm{Al}_{2} \mathrm{O}_{3}$. Figs. 6 and 7 both display the diffraction profiles of transition alumina nanoparticles compacted at $5 \mathrm{GPa}$ in DAC. One can distinguish a large Gaussian peak in the range [3-4.5] $\mathrm{nm}^{-1}$, the two peaks characteristic of the $\gamma$-phase being less visible in comparison to the initial powder. This can be attributed to an increase of intensities of the peaks relative to the $\delta^{*}$-phase, at $3.85 \mathrm{~nm}^{-1}$ (114) and $4.07 \mathrm{~nm}^{-1}$ (311), thus making the minima between the $\gamma$ peaks higher, see Fig. 7. This effect is even more pronounced on the diffraction profile of the sample compacted at $20 \mathrm{GPa}$. Simultaneously, the peak at $5 \mathrm{~nm}^{-1}$ first increases (from 0 to $5 \mathrm{GPa}$ ) and then decreases. Unfortunately, this peak is present in the simulated profiles for both $\gamma-\mathrm{Al}_{2} \mathrm{O}_{3}$ and $\delta^{*}-\mathrm{Al}_{2} \mathrm{O}_{3}$. The decrease is compatible with a phase transformation from $\gamma$ to $\delta^{*}$. The increase at low pressure could therefore be attributed to the texturation observed. 

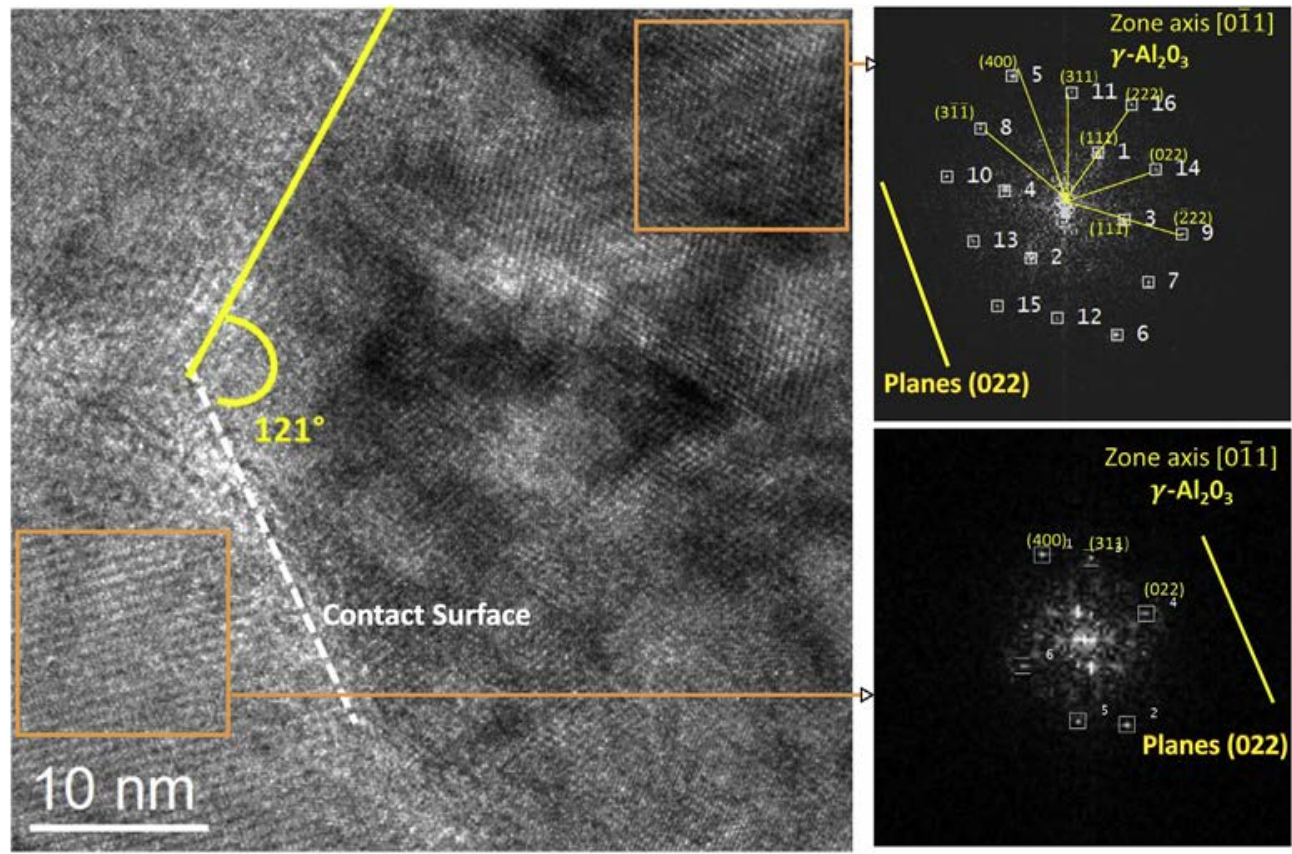

Fig. 4. HRTEM image of deformed nanoparticles. The indexation of the Fast Fourier Transform shows that nanoparticles are in the $\gamma$-phase with $\{220\}$ planes parallel to the contact surface.

Table 1

Number of indexed particles, with the crystallographic phases and orientations, obtained for each pressure applied in the DAC. Two phases are indicated in the same line when they are found in the same nanoparticle.

\begin{tabular}{llll}
\hline Pressure & Phases & Number of nanoparticles & Specific crystallographic orientation \\
\hline $5 \mathrm{GPa}$ & $\gamma-\mathrm{Al}_{2} \mathrm{O}_{3}$ & 15 & $\{220\} / /$ contact surface \\
\hline $15 \mathrm{GPa}$ & $\gamma-\mathrm{Al}_{2} \mathrm{O}_{3}$ & 8 & $\{220\} / /$ contact surface \\
& $\delta$ & 10 & \\
\hline $20 \mathrm{GPa}$ & $\gamma-\mathrm{Al}_{2} \mathrm{O}_{3}+\delta^{*}-\mathrm{Al}_{2} \mathrm{O}_{3}$ & 2 & $\{220\} / /$ solicitation axis in DAC \\
& $\gamma-\mathrm{Al}_{2} \mathrm{O}_{3}$ & 3 & $\{117\}$ at $20^{\circ}$ from the solicitation axis \\
\hline & $\delta^{*}-\mathrm{Al}_{2} \mathrm{O}_{3}$ & 3 & \\
\hline
\end{tabular}
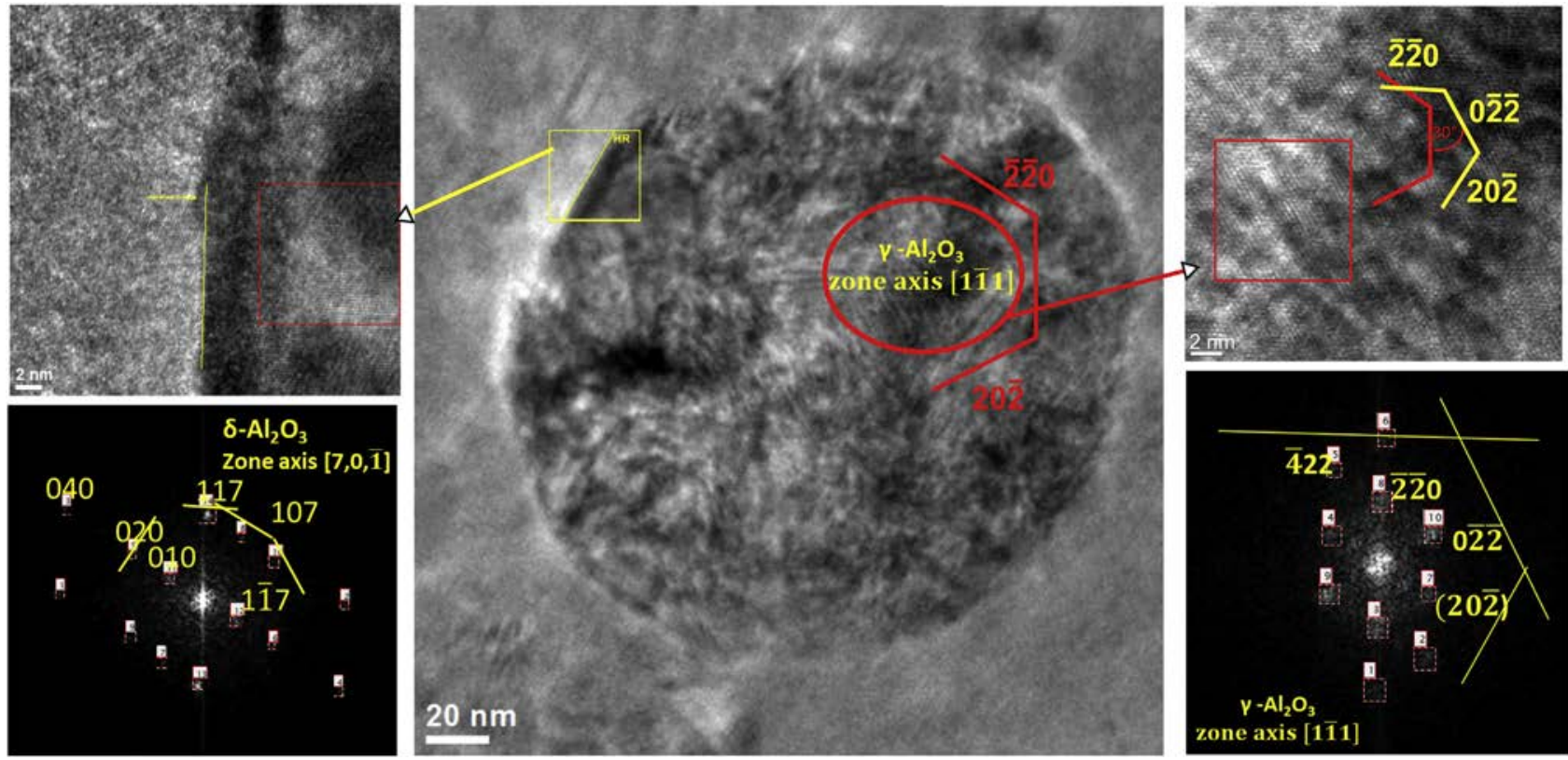

Fig. 5. HRTEM image of a deformed nanoparticle in the sample compacted at $20 \mathrm{GPa}$. Two regions of interest are studied and the corresponding FFT indexations reveal the phase $\gamma$ $\mathrm{Al}_{2} \mathrm{O}_{3}$ near the core of the nanoparticle and the phase $\delta^{-} \mathrm{Al}_{2} \mathrm{O}_{3}$ near the surface. 

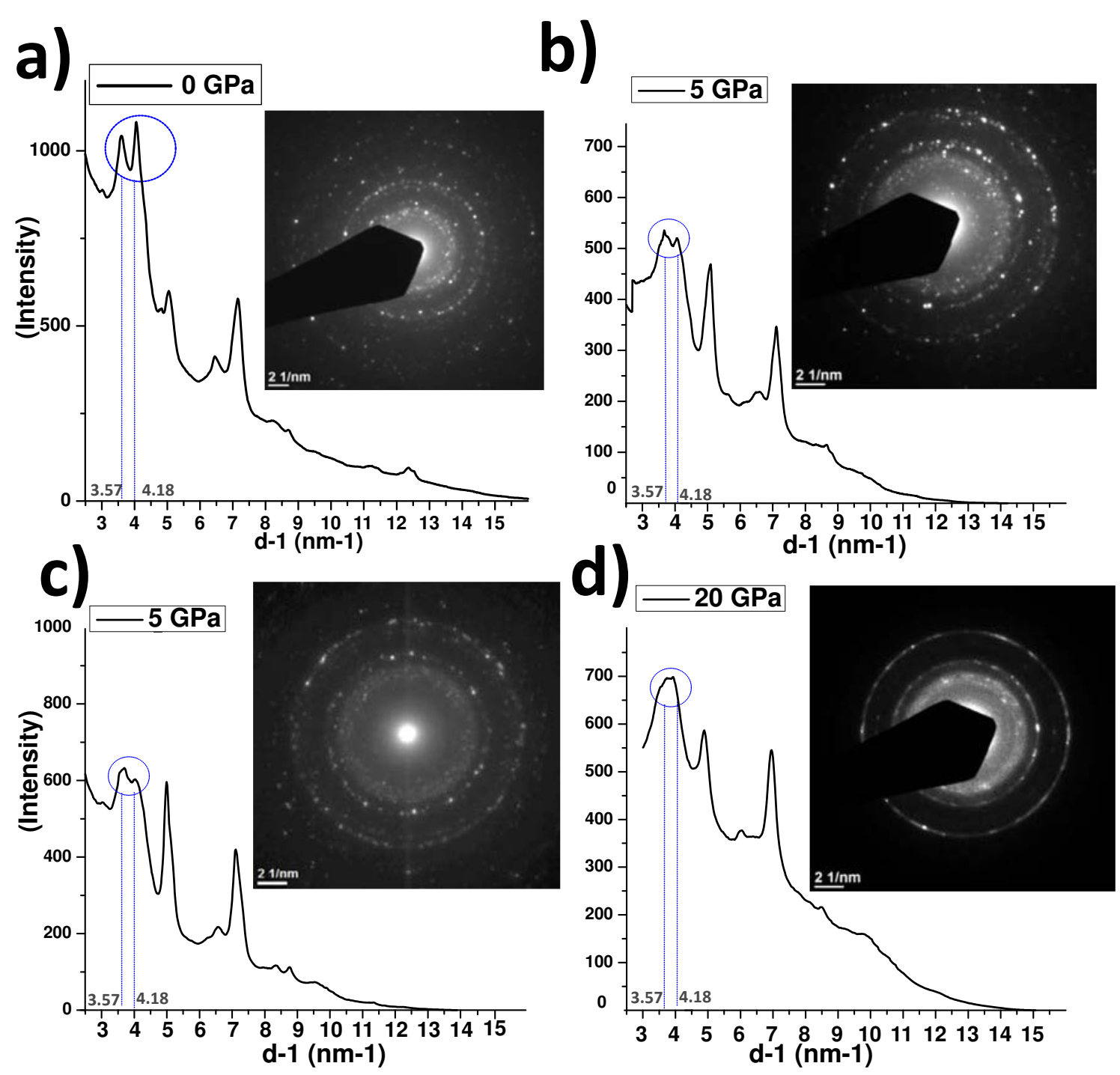

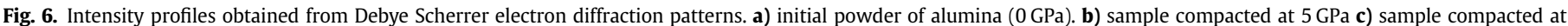

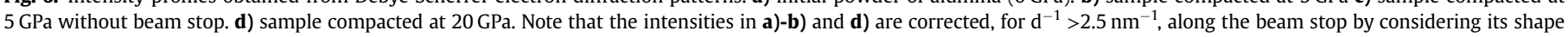
(correction of the length of each ring).

\section{Discussion}

\subsection{Preferential orientation and deformation mechanism}

At $5 \mathrm{GPa}$, the deformation of only the smallest nanoparticles can be explained by the fact that the local pressure is higher on smaller nanoparticles than on bigger ones, and $5 \mathrm{GPa}$ may not be large enough to deform larger nanoparticles - on the contrary to what is observed at 15 and $20 \mathrm{GPa}$, where all the particles are deformed. Moreover, as bulk alumina is known to be brittle at room temperature, it is worthy to notice that no fracture can be observed in the nanoparticles, even after compaction at $20 \mathrm{GPa}$. Our results are in agreement with the in situ observations of Calvié et al. [1]. However, Zheng et al. evidenced that the electron beam could facilitate plasticity in silica [31]. As compaction in the DAC is carried out without any irradiation, it can be concluded that plastic deformation really occurs in alumina nanoparticles at ambient and that it is not a possible artifact due to the electron beam in Calvié's experiments.

Facets are clearly visible in a lot of deformed nanoparticles. They are found to be parallel to each other and parallel to the principal solicitation direction, at least close to the surface. Their preferential orientation is not clearly visible deeper in the compacted samples. This may be attributed to the fact that the uniaxial force is not integrally transferred - in value and direction - at a certain distance below the surface. Indeed, it is known that arches can be formed in granular assembly of nanoparticles [32].

Regarding the orientation of the $\{220\}$ planes in the deformed particles in the $\gamma$-phase, the results obtained suggest that nanoparticles may rotate prior to or at the early stages of compression, similarly to grain boundary rotation in strained polycrystalline materials $[33,34]$. Rotation would enable one plane of the family $\{220\}$ to become parallel to the surface in contact with another particle. These planes can give rise to the facets observed in Fig. 3. They also indicate that the nanoparticles are deformed along the compression axis $<110>$.

The analysis performed on the nanoparticles compacted in the DAC can bring useful pieces of information on the behavior of individual nanoparticles during in situ TEM nano-compression tests, as published by Calvié et al. [25]. First, it has to be mention that 


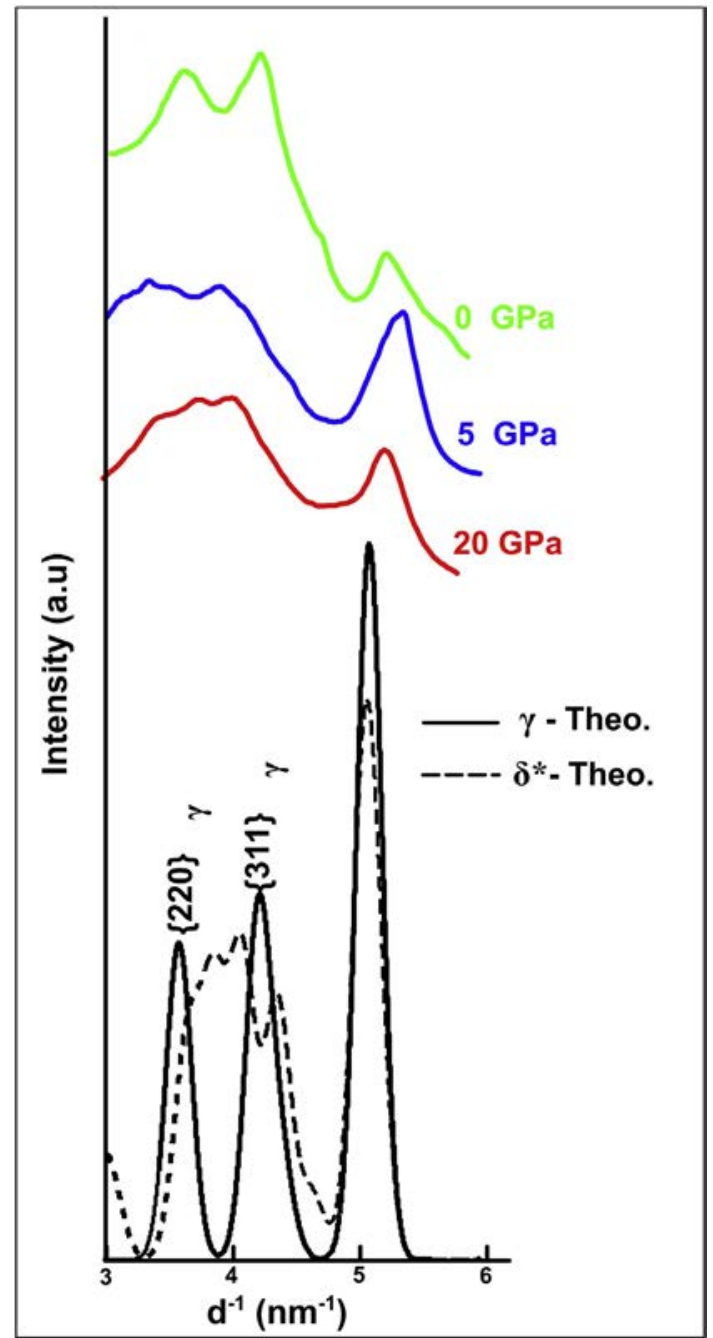

Fig. 7. Evolution of the intensity measured on Debye Scherrer diffraction patterns as a function of the applied pressure, for $\mathrm{d}^{-1}$ ranging from 3 to $5.5 \mathrm{~nm}^{-1}$. The theoretical electron diffraction profiles of one unit cell of $\gamma-\mathrm{Al}_{2} \mathrm{O}_{3}$ and one unit cell of $\delta^{*}-\mathrm{Al}_{2} \mathrm{O}_{3}$ are also represented.

movies acquired on these nanoparticles tests often show a slight rotation of the nanoparticle at the early beginning of the compression test. Such rotation may initially be attributed to a nonperfect alignment of the diamond tip and the sapphire substrate but thanks to DAC, the rotation can also be attributed to a first event before or at the beginning of the deformation mechanism. Indeed, the available tests show that during uniaxial compression, slip bands oriented at $\sim 35^{\circ}$ with respect to the compression axis appear during plastic deformation (see Fig. 8). This measure is a possible value of the angle between $\{220\}$ and $\{111\}$ planes in $\gamma-\mathrm{Al}_{2} \mathrm{O}_{3}$. By drawing a comparison with the DAC experiments, it can be strongly suggested that the slip bands correspond to the $\{111\}$ planes and the compression axis to the $<110>$ direction. Thus, if one plane from the $\{220\}$ family is parallel to the solicitation direction, two other ones are parallel to the surfaces of the nanoparticle which are in contact with the diamond punch and the sapphire substrate. As a consequence, the nanoparticle is thought to first rotate from its initial random orientation to a preferential orientation, where one of the $\{220\}$ planes becomes parallel to the compression axis, as in Fig. 3. After rotation, the orientation of the nanoparticle permits the activation of the $\langle 110\rangle\{111\}$ slip system, dominant in a spinel structure [35]. This preferential orientation is also in agreement with the results published by Coleman et al., who showed that the surface energy of the $\{220\}$ is lower than that of the $\{111\}$ and $\{001\}$ planes in $\gamma-\mathrm{Al}_{2} \mathrm{O}_{3}$ at room temperature [36].

\subsection{Phase transformation}

The phase indexation summarized in Table 1 reveals that at low pressure, all the deformed particles that have been indexed are in the $\gamma$-phase. Nevertheless, it cannot exclude that other nanoparticles in the $\delta^{*}$-phase could be deformed too. At higher pressures, the $\delta$-phase has been evidenced. As this phase was not present in the sample before compression, the results suggest that phase transformation may occur under pressure even at ambient temperature. Indeed, contact pressures between the nanoparticles can locally be very high. $\alpha$ alumina has been found to change its structure at $90 \mathrm{GPa}$ [24] and we may expect the same behavior for transition alumina phases, which are necessarily less stable due to the disordering of aluminum vacancies.

The particle shown in Fig. 5 may be a good example of phase transformation under pressure. Because the $\gamma$-phase is found in the center of the nanoparticle, it can reasonably be assumed that it was originally in the $\gamma$-phase. The $\delta$-phase, not present in the native state, can therefore be considered as the result of phase transformation, which most probably occurs first in the contact area where the stress is maximum. This is in agreement with a recent study published by Girão et al., who evidenced a propagation of phase transformation in $\mathrm{SnO}_{2}$ nanoparticles from the surface to the core of the nanoparticles [37].

The quantification of the Debye Scherrer electron patterns, at different pressures, evidence phase transformation under pressure. Indeed, the intensity profile changes with pressure in the $3-5.5 \mathrm{~nm}^{-1}$ range of $\mathrm{d}^{-1}$, the progressive increase of the minimum between the peaks relative to the $\gamma$-phase at 3.57 and $4.18 \mathrm{~nm}^{-1}$ indeed suggests a higher fraction of $\delta^{*}$ phase in the compacted samples. Moreover, the intensity decrease at high pressure of the peak at $5 \mathrm{~nm}^{-1}$ plays in favour of a higher fraction of the $\delta^{*}$ phase. From this qualitative analysis of the diffraction profiles, it can therefore be proposed that phase transformation occurs during compaction of transition alumina nanoparticles at room temperature in DAC, even at $5 \mathrm{GPa}$. This phase transformation becomes more important when the pressure of compaction in DAC is increased to $20 \mathrm{GPa}$.

A quantification of the fractions of the $\gamma$ and $\delta^{*}$ phases in each sample might be investigated in order to assess the effect of pressure. For several reasons listed hereafter, we think that the simulation results are not accurate and cannot be presented here. Indeed, the diffracted intensities depend on the electron scattering factor, which highly varies with atom ionisations. It would be difficult to determine the electron scattering factor in the case of an ionocovalent compound such as $\mathrm{Al}_{2} \mathrm{O}_{3}$. Moreover, the peak intensities depend on the crystal size. When considering that only a part of the nanoparticles undergo phase transformation, the crystal size for the $\delta^{*}$ phase would be different from that of the $\gamma$ phase. Associated to the subtraction of the background, the uncertainties on the electron scattering factor value and on the crystal size for each phase do not permit an accurate quantification at different pressures. Nevertheless, the experimental profiles shown in Fig. 7 clearly suggest an increase of the fraction of $\delta^{*}-\mathrm{Al}_{2} \mathrm{O}_{3}$ when increasing the pressure in the DAC, which is compatible with the HRTEM indexations of compacted nanoparticles. Those consistent results assert that a phase transformation following the sequence $\gamma-\mathrm{Al}_{2} \mathrm{O}_{3} \rightarrow \delta^{*} \mathrm{Al}_{2} \mathrm{O}_{3}$ occurs at room temperature when increasing the pressure in the DAC.

The physical parameters that trigger phase transformation between the different transition alumina are not yet fully known. In 

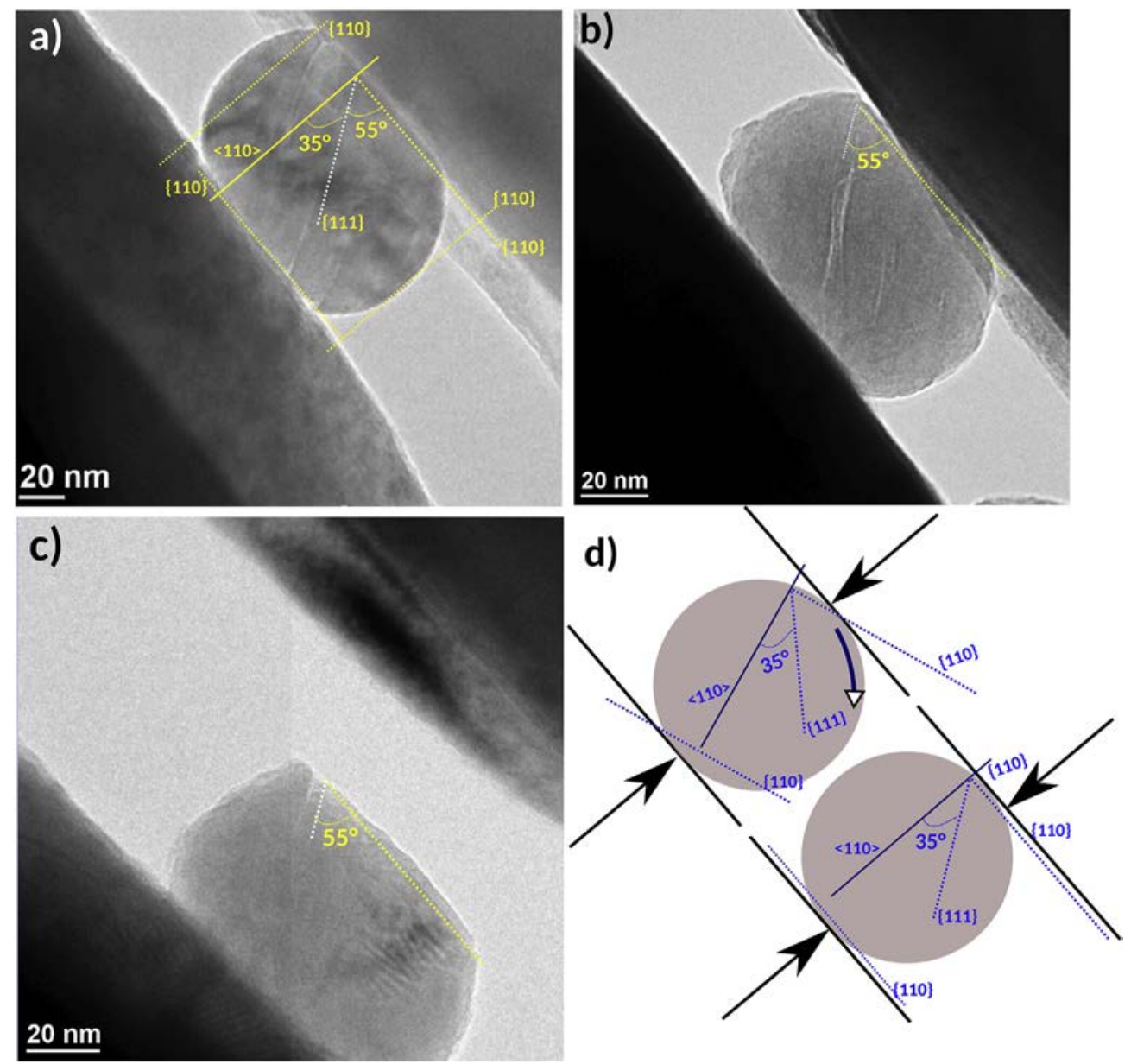

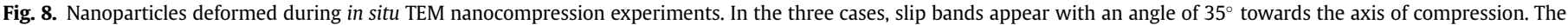
value of the angle is consistent with the value between (111) plane and $<110>$ direction.

all phases, the oxygen atoms are nearly in a face-centered cubic arrangement so phase transformation can reasonably be thought to imply the aluminum atoms and their vacancies. These aluminum atoms occupy tetrahedral and octahedral sites in the $\gamma$-phase, which is the most disordered one [29], whereas only octahedral sites are occupied in the $\alpha$-phase, the most stable one at bulk. We proposed above that plastic deformation occurs through a shear mechanism in the $\{111\}$ planes, probably governed by perfect dislocation gliding (no stacking fault detected). As some of these planes contain layers rich in tetrahedral sites, it is suggested that shear in the $\{111\}$ planes induces aluminum displacements and therefore of the aluminum vacancies, so as to stabilize the structure thanks to a preferential rearrangement of tetrahedral sites. This mechanism would be in agreement with a better thermodynamic equilibrium of the phases $\delta^{*}$ and $\delta$.

Phase transformation can occur under pressure and temperature: Liao et al. [17] showed that a pressure increase reduces the temperature of phase transformation to $\alpha-\mathrm{Al}_{2} \mathrm{O}_{3}$. As we observe phase transformation at ambient temperature, it seems that the curve proposed by Liao et al. can be extrapolated to high pressures (20 GPa or more), and that phase transformation can occur also at ambient temperature.

\section{Conclusion}

DAC compression experiments coupled with FIB sample preparation and TEM observations techniques are very interesting for the study of deformation and phase transformation under pressure. HRTEM observations of compacted samples under $5 \mathrm{GPa}$, $15 \mathrm{GPa}$ and $20 \mathrm{GPa}$ show a faceting of the nanoparticles parallel to the solicitation direction with a preferential crystallographic orientation of the $\{220\}$ planes for the $\gamma$ phase. This particular family plane is also involved in the plastic behavior observed during nanocompression tests in TEM. Indeed, the $<110>\{111\}$ slip system, dominant in a spinel structure, is the active one and leads to severe plastic deformation. Our results also reveal that phase transformation from $\gamma-\mathrm{Al}_{2} \mathrm{O}_{3}$ to $\delta^{*}-\mathrm{Al}_{2} \mathrm{O}_{3}$ (and then to $\delta-\mathrm{Al}_{2} \mathrm{O}_{3}$ ) occurs under pressure at ambient temperature. Both phases may coexist in the same nanoparticle, $\delta^{*}-\mathrm{Al}_{2} \mathrm{O}_{3}$ or $\delta-\mathrm{Al}_{2} \mathrm{O}_{3}$ appearing at the contact periphery with another nanoparticle where the stress is maximum.

Room temperature plasticity in transition alumina nanoparticles may explain the very high densities of the compacted samples, studied either in the literature [17] or in the present paper (sample compacted at $20 \mathrm{GPa}$ ). By taking advantage of the deformation mechanism and phase transformation, it could be possible to optimize the compaction and sintering conditions - pressure, temperature, nanoparticle size - used for ceramic fabrication.

\section{Acknowledgements}

The authors acknowledge the Consortium Lyon Saint-Etienne de Microscopie (CLYM) for the access to the microscope. 


\section{Appendix A. Supplementary data}

Supplementary data related to this article can be found at https://doi.org/10.1016/j.actamat.2018.03.023.

\section{Declarations of interest}

None.

\section{References}

[1] E. Calvié, J. Réthoré, L. Joly-Pottuz, S. Meille, J. Chevalier, V. Garnier, Y. Jorand, C. Esnouf, T. Epicier, J.B. Quirk, K. Masenelli-Varlot, Mechanical behavior law of ceramic nanoparticles from Transmission electron microscopy in situ nanocompression tests, Mater. Lett. 119 (2014) 107-110.

[2] I. Issa, J. Amodeo, J. Réthoré, L. Joly-Pottuz, C. Esnouf, J. Morthomas, M. Perez, J. Chevalier, K. Masenelli-Varlot, In situ investigation of $\mathrm{MgO}$ nanocube deformation at room temperature, Acta Mater. 86 (2015) 295-304.

[3] G. Sh, Boltachev, K.E. Lukyashin, A.L Maximenko, R.N Maksimov, V. A Shitov, M.B. Shtern, Compaction and flow rule of oxide nanopowders, Opt. Mater. 71 (2017) 145-150.

[4] R.S. Lima, B.R. Marple, Thermal spray coatings engineered from nanostructured ceramic agglomerated powders for structural, thermal barrier and biomedical applications: a review, J. Therm. Spray Technol. 16 (2007) 40-63.

[5] S. Singh, S. Ramakrishna, R. Singh, Material issues in additive manufacturing: a review, J. Manuf. Process. 25 (2017) 185-200.

[6] J.R. Rodrigues, N.M. Alves, J.F. Mano, Nacre-inspired nanocomposites produced using layer-by-layer assembly : design strategies and biomedical applications, Mater. Sci. Eng. C 76 (2017) 1263-1273.

[7] M. Sokol, M. Halabi, Y. Mordekovitz, S. Kalabukhov, S. Hayun, N. Frage, An inverse Hall-Petch relation in nanocrystalline $\mathrm{MgAl}_{2} \mathrm{O}_{4}$ spinel consolidated by high pressure spark plasma sintering (HSPS), Scripta Mater. 139 (2017) 159-161.

[8] R. Apetz, M.P.B. van Bruggen, Transparent alumina: a light scattering model, J. Am. Ceram. Soc. 86 (2003) 480-486.

[9] A. Krell, J. Klimke, T. Hutzler, Transparent compact ceramics: inherent physical issues, Opt. Mater. 31 (2009) 1141-1150.

[10] N. Roussel, L. Lallemant, J.Y. Chane-Ching, S. Guillemet-Fristch, B. Durand, V. Garnier, G. Bonnefont, G. Fantozzi, L. Bonneau, S. Trombert, D. GarciaGutierrez, Highly dense, transparent $\alpha-\mathrm{Al}_{2} \mathrm{O}_{3}$ ceramics from ultrafine nanoparticles via a standard SPS sintering, J. Am. Ceram. Soc. 96 (2013) 1039-1042.

[11] S. Ghanizadeh, S. Grasso, P. Ramanujam, B. Vaidhyanathan, J. Binner, P. Brown, J. Goldwasser, Improved transparency and hardness in $\alpha$-alumina ceramics fabricated by high-pressure SPS of nanopowders, Ceram. Int. 43 (2017) $275-281$.

[12] A. Ikesue, Y.L Aung Ceramic laser materials, Nat, Photon, 2 (2008) 721-727.

[13] J.S. Ponraj, S.C. Dhanabalan, G. Attolini, G. Salviati, SiC nanostructures toward biomedical application and its future challenges, Crit. Rev. Solid State Mater. Sci. 41 (2016) 430-446.

[14] S. Korte, W.J. Clegg, Discussion of the dependence of the effect of size on the yield stress in hard materials studied by microcompression of $\mathrm{MgO}$, Phil. Mag. 91 (2011) 1150-1162.

[15] S. Kiani, C. Ratsch, A.M. Minor, S. Kodambaka, J.M. Yang, Orientation- and sizedependent room-temperature plasticity in ZrC crystals, Phil. Mag. 95 (2015) 985-997.

[16] B. Chen, D. Penwell, L.R. Benedetti, R. Jeanloz, M.B. Kruger, Particle-size effect on the compressibility of nanocrystalline alumina, Phys. Rev. B 66 (2002)
144101

[17] S.C. Liao, YJ. Chen, B.H. Kear, W.E. Mayo, High pressure/low temperature sintering of nanocrystalline alumina, Nanostruct. Mater. 10 (1998) 1063-1079.

[18] D. Fargeot, D. Mercurio, A. Dauger, Structural Characterization of alumina metastable phases in plasma sprayed deposits, Mater. Chem. Phys. 24 (1990) 299-314.

[19] I. Levin, D. Brandon, Metastable alumina polymorphs: crystal structures and transition sequences, J. Am. Ceram. Soc. 81 (1998) 1995-2012.

[20] J.M. McHale, A. Auroux, A.J. Perrotta, A. Navrotsky, Surface energies and thermodynamic phase stability in nanocrystalline aluminas, Science 277 (1997) 788-791.

[21] Y. Repelin, E. Husson, Etudes structurales d'alumines de transition. I-alumines gamma et delta, Mater. Res. Bull. 25 (1990) 611-621.

[22] M.I.F. Macêdo, C.A. Bertran, C.C. Osawa, Kinetics of the $\gamma \rightarrow \alpha$-alumina phase transformation by quantitative X-ray diffraction, J. Mater. Sci. 42 (2007) 2830-2836.

[23] G. Paglia, C.E. Buckley, A.L. Rohl, R.D. Hart, K. Winter, A.J. Studer, B.A. Hunter J.V. Hanna, Boehmite derived $\gamma$-alumina system. 1. Structural evolution with temperature, with the identification and structural determination of a new transition phase, $\gamma^{\prime}$-alumina, Chem. Mater. 16 (2004) 220-236.

[24] J.F. Lin, O. Degtyareva, C.T. Prewitt, P. Dera, N. Sata, E. Gregoryanz, H.K. Mao, R.J. Hemley, Crystal structure of a high-pressure/high-temperature phase of alumina by in situ X-ray diffraction, Nat. Mater. 3 (2004) 389-393.

[25] E. Calvié, J. Réthoré, L. Joly-Pottuz, S. Meille, J. Chevalier, V. Garnier, Y. Jorand C. Esnouf, T. Epicier, K. Masenelli-Varlot, Mechanical behavior law of ceramic nanoparticles from Transmission Electron Microscopy in situ nanocompression tests, Mater. Lett. 119 (2014) 107-110.

[26] M. Azar, P. Palmero, M. Lombardi, V. Garnier, L. Montanaro, G. Fantozzi, J. Chevalier, Effect of initial particle packing on the sintering of nanostructured transition alumina, J. Eur. Ceram. Soc. 28 (2008) 1121-1128.

[27] S. Cottrino, Y. Jorand, J. Adrien, C. Olagnon, Spray-drying of highly concentrated nano alumina dispersions, Powder Technol. 237 (2013) 586-593.

[28] A. Girard, J. Margueritat, D. Machon, L. Saviot, F. Demoisson, A. Mermet Contact laws between nanoparticles : the elasticity of a nanopowder, Nanoscale 10 (2018) 2154

[29] R.S. Zhou, R.L. Snyder, Structures and transformation mechanisms of the $\eta$, $\gamma$ and $\theta$ transition aluminas, Acta Crystallogr. B 47 (1991) 617-630.

[30] P.A. Stadelmann, EMS - a software package for electron diffraction analysis and HREM image simulation in materials science, Ultramicroscopy 21 (1987) 131-145. http://www.jems.sas.ch. (Accessed 8 December 2017).

[31] K. Zheng, C. Wang, Y.Q. Cheng, Y. Yue, X. Han, Z. Zhang, Z. Shan, S.X. Mao M. Ye, Y. Yin, E. Ma, Electron-beam-assisted superplastic shaping of nanoscale amorphous silica, Nat. Commun. 1 (2010) 24.

[32] M. Nicodemi, Force correlations and arch formation in granular assemblies, Phys. Rev. Lett. 80 (1998) 1340-1343.

[33] M. Upmanyu, D.J. Srolovitz, A.E. Lobkovsky, J.A. Warren, W.C. Carter, Simultaneous grain boundary migration and grain rotation, Acta Mater. 54 (2006) 1707-1719.

[34] M. Legros, D.S. Gianola, K.J. Hemker, In situ TEM observations of fast grainboundary motion in stressed nanocrystalline aluminum films, Acta Mater. 56 (2008) 3380-3393.

[35] R.C. Bradt, C.A. Brookes, J.L. Routbort, The brittle-to-ductile transition in $\mathrm{MgAl}_{2} \mathrm{O}_{4}$ spinel, in: Plastic Deformation of Ceramics, Springer Science \& Business Media, 2013.

[36] S.P. Coleman, D.E. Spearot, Atomistic simulation and virtual diffraction characterization of stable and metastable alumina surfaces, Acta Mater. 78 (2014) 354-368.

[37] H.T. Girão, T. Cornier, S. Daniele, R. Debord, M.A. Caravaca, R.A. Casali, P. Mélinon, D. Machon, Pressure-induced disordering in $\mathrm{SnO}_{2}$ nanoparticles, J. Phys. Chem. C 121 (2017) 15463-15471. 